\title{
Parental Stress among Parents of Children with Learning Disabilities
}

Shaluni a/p Anpalagan, Yusni Mohamad Yusop, Zaida Nor Zainudin, Wan Norhayati Wan Othman, Dharatun Nisa Fuad M. Kari, Shahlan Surat

To Link this Article: http://dx.doi.org/10.6007/IJARBSS/v11-i12/11754 DOI:10.6007/IJARBSS/v11-i12/11754

Received: 11 October 2021, Revised: 14 November 2021, Accepted: 30 November 2021

Published Online: 13 December 2021

In-Text Citation: (Anpalagan et al., 2021)

To Cite this Article: Anpalagan, S. a/p, Yusop, Y. M., Zainudin, Z. N., Othman, W. N. W., Kari, D. N. F. M., \& Surat, S. (2021). Parental Stress among Parents of Children with Learning Disabilities. International Journal of Academic Research in Business and Social Sciences, 11(12), 63-77.

Copyright: (C) 2021 The Author(s)

Published by Human Resource Management Academic Research Society (www.hrmars.com)

This article is published under the Creative Commons Attribution (CC BY 4.0) license. Anyone may reproduce, distribute, translate and create derivative works of this article (for both commercial and non0-commercial purposes), subject to full attribution to the original publication and authors. The full terms of this license may be seen

at: http://creativecommons.org/licences/by/4.0/legalcode

Vol. 11, No. 12, 2021, Pg. $63-77$

Full Terms \& Conditions of access and use can be found at http://hrmars.com/index.php/pages/detail/publication-ethics 


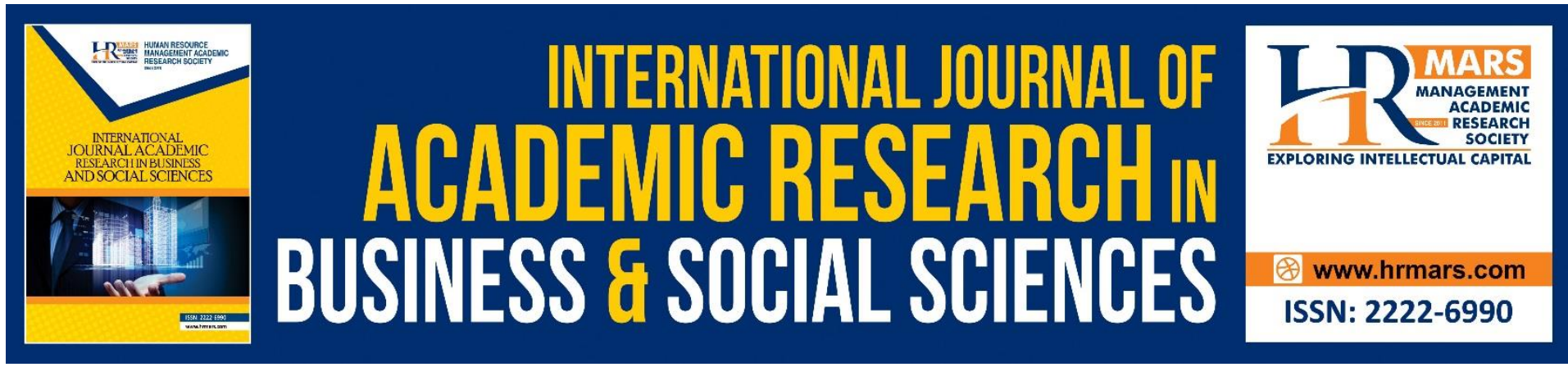

\title{
Parental Stress among Parents of Children with Learning Disabilities
}

\author{
Shaluni a/p Anpalagan, Yusni Mohamad Yusop (Ph.D), Zaida \\ Nor Zainudin, (Ph.D), Wan Norhayati Wan Othman (Ph.D), \\ Dharatun Nisa Fuad M. Kari (Ph.D), Shahlan Surat (Ph.D) \\ Faculty of Educational Studies, UPM Malaysia, Faculty of Education, UKM Malaysia
}

\begin{abstract}
Parents of children with learning disabilities such as Late Global Development, Down syndrome and Intellectual Disabilities experience parental stress as a result of adjusting and coping with their children's conditions. Therefore, this study aims to analyses the level of parental stress among parents with learning difficulties and the differences in parents and children's gender with parental stress level. A probability sample method was implemented in this study to determine the level of stress among parents of children with learning disabilities. Parental Stress Index/Short Form instrument was used in this study to determine the parental stress level. A total of 120 respondents among parents of children with learning difficulties has participated in this study. The results showed level of parental stress among parents of children with learning difficulties is $97.5 \%$ or 117 parents out of 120 participants with children with learning difficulties falls under typical stress category, $2.5 \%$ or only 3 parents reported to have High Stress Category and none reported to have clinically significant stress. As for the differences in gender among parents, result shows that there is no significant differences among both parent's gender and children $s$ gender with parental stress. Both father and mother faces almost the equal amount of stress and children s gender does not differ in parental stress.
\end{abstract}

Keywords: Learning Difficulties, Disability, Difficult Child, Parental, Stress.

\section{Introduction}

Referring to Malaysia Department of Social Welfare, children who diagnosed with Global Developmental Delay (GDD), Attention Deficit Hyperactivity Disorder (ADHD), Autism, Down syndrome, Intellectual Disability, and Specific Learning Disability (Specific LD) are classified under the Learning Disability category.

Parenting is one of the most challenging responsibilities in one's life as it is the most essential relationship in family which provides a platform for development of a child across the lifespan. However, parenting can be stressful at times especially having children with disabilities (Miller \& Chen, 2010). There are many research have reported that parents of children with disorder or disabilities experience significantly more parenting stress than parents of children without disabilities (Baker \& Blacher, 2002) Also it is indicated that the 
severity of the disabilities determines the level of stress of parents. (Keller, \& Honig, 2004). Raising children with disabilities or special needs can be an overwhelming experience for families especially parents as it can significantly affects parent's life in most of the aspects including job, mental and physical health, financially, social and family relationship.

Challenges such as financial constraint may arise as there will be additional expenses of medicine, proper food and others for children. Most parents had to sacrifices the career for their children which results in poverty and unable to meet the household needs. Some families had to depend solely on one partner s income whereas the other had to stay home and take care of the child. As a whole parents become more fatigue and experience loss of leisure time due to taking care of children and more responsibilities that increases (Badger, 1996).

Many studies has been conducted and shows that more psychological support is provided for the affected children however parents do not receive adequate support in terms of psychological and emotional support from the moment parents get to know about their children diagnosis. (Babic \& Leutar, 2014). Parents are also often concerned and worried by the density of caring responsibilities that been required time and a lot of work and energy and parent also must be available most of time to cater the need and meet the daily needs of the child which this might affect their career (Bahry et al., 2019).

There are many more issues that will leave parents in puzzle such as not knowing about how to handle the children according to the disorder. Some parents are often blamed to be responsible for the child behavior or disorder. Many are often misjudged as spoiling their children by not being strict and if the children behave strangely. Parents also do not receive satisfactory support from the community especially neighbors and friends even close family members. Therefore it is also proved that having special need children in the family, parents social life is affected or disrupted due to the amount of time spend catering and monitoring the children. Some may avoid going to social gathering due to the disturbing and uncontrollable behavior of their children (Bahry et al., 2019).

\section{Research Objective}

- To Determine the level of parental stress among parents of children with learning disabilities:

- 1 a: To determine the level of Parental Distress among parents of children with learning disabilities.

- $1 \mathrm{~b}$ : To determine the level of Parent Child Dysfunctional Interaction among parents of children with learning disabilities.

- $1 \mathrm{c}$ : To determine the level of Difficult Child among parents of children with learning disabilities.

- 2. To determine the differences between parents gender and parental stress among parents of children with learning disabilities.

- 3. To determine the differences between children $s$ gender and parental stress among children with learning disabilities.

\section{Research Question and Hypothesis}

- What is the level of parental stress among parents of children with learning disabilities?

- 1a: What is the level of Parental Distress among parents of children with learning disabilities? 
- $1 \mathrm{~b}$ : What is the level of Parent Child Dysfunctional Interaction among parents of children with learning disabilities?

- 1c: What is the level of Difficult Child among parents of children with learning disabilities?

- 2. Hypothesis Alternative 1: There is a significant differences between parent's gender and parental stress among parents of children with learning disabilities.

- 3. Hypothesis Alternative 2: There is a significant differences between children $\mathrm{s}$ gender and parental stress among children with learning disabilities.

\section{Literature Review \\ Learning Disabilities}

Learning disabilities among children are commonly well-defined as interruptions or delayed in developing age appropriate behavior, thinking, social skills or regulation of emotions. All these delayed and disrupted ability will affect their functioning at home, school as well as other social situation. Some of the symptoms may vary as a kid develops, and may include issues with how a child plays, learns, communicates, and acts, as well as difficulties with how the child manages their emotions. Symptoms often appear in early childhood, however certain diseases may emerge throughout the adolescent years. The diagnosis is frequently made during the school years, and sometimes earlier. However, some children with a mental disorder are diagnosed sooner (Petretto \& Masala, 2017).

\section{Parental Stress among Parents of Children with Disabilities}

Parental stress refers to the level of stress experienced by parents due to the relationship between parents and children (Solis \& Abidin, 1990). Parental stress will be measured in this study by using Parental Stress Index (PSI-SF) (Solis \& Abidin, 1990). High scores indicated the high level of stress facing by parent due the mental illness of their children. Many research generally shows that parenthood is often connected with important changes in parents' life and parenting in itself can be stressful. Moreover parental stress has a great impact on parent's health and wellbeing besides than that the quality of the relationship between partner, family member and with the child itself are affected.

Many studies also proved that parents who has child with mental disabilities experience higher levels of stress compared to parents with children with a normal development (Delambo et al., 2013). This is because having a child with disabilities involves more effort and involvement from parents such as long term commitment of therapies and medical treatments. This can be continued till the child reached the adolescent and adulthood which the stress also differ in a greater impact. All together this could create a long-lasting stress that causes chaotic and difficulties in the family.

In a another study conducted to measure parental stress among and fathers of children who have Autism Spectrum Disorder (ASD), stress indicates that the mothers with children who have deficits in social skills can have a profound impact on parental stress compare to fathers. According to Davis and Carter they affirm that mothers of children with poor social skills are having more parenting stress. Besides that, children with ASD who has poor levels of the communication skills also impacts the mother more than fathers (Soltanifar, 2009).

In addition, parents are blamed as children illness are often seen as one of the factor by genetic or inherited from parents. Besides that when families do not seek treatment for a parent's mental disturbance or seek for adequately support their children have the tendency 
to experience the effects of such mental illness, self-blame on the part of the child may heighten these other risk mechanisms to produce vulnerability. (Beardslee, Versage, \& Gladstone, 1998). In 20th century it is often said that poor parenting also could be the reason for most forms of mental disorders such as like autism, schizophrenia and depression and, more recently, attention-deficit, hyperactivity disorder, or ADHD.

Moreover families who has offspring or family members with mental illness frequently associated with parenting or parents faulty in discipline and socialization. Blaming the parents for such matters has been a central premise of twentieth-century thought as the misconceptions of mental illness, therefore it has become one of the reason for why families have been and continue to be hesitant to seek diagnosis or therapy for their children's emotional and behavioural problems. (Hinshawet, 2001). Additionally parents of family often keep this mental disorder of a child as a secret out of embarrassment (Akbarzadeh, 2015).

\section{Parent Distress (PD)}

The aspects of parenting comprises the aspects concerning the child's growth and development, behavioural and social issues, emotional well-being, and financial obligations which the concerns about this aspects often can resulted in parental distress (Ross \& Blanc, 1998). Some other factors that often associated with parental distress will be child with mental health problems or disabilities, which challenges that often faced by parents of children with disabilities problems have been associated with parental distress and emotional state of being strained beyond their boundary (Podolski \& Nigg, 2001; Sharpley \& Bitsika, 1997).

\section{Parent-Child Dysfunctional Interaction (PCDI)}

According to Solis \& Abiddin, 1995, The Parent-Child Dysfunctional Interaction (PCDI) refers to in light of their expectations regarding the parent-child connection, a parent's views about the emotional quality of his or her relationship with their children. As for parents with disable child, especially children with learning disabilities will have communication which will be the barrier which indirectly can lead to dysfunctional interaction.

\section{Difficult Child (DC)}

According to Abiddin, difficult child refers to the behavioral characteristics that make the child easy or difficult to manage. Meanwhile, the sub-scale of DC refers to parents' perception of how difficult or easy their child is in Parental Stress Index Instrument. (Bishop et al. 2007). One of the reason that often contribute to parent stress is the child s behavior especially children with special needs such as ASD as their characteristics are often impaired in adaptive and daily functioning which require extra effort to care and assist their children in daily routine task such as getting dressed, eating, and daily hygiene (Herring et al. 2006). In addition, children with Learning Disabilities, often also reported to have insomnia or sleeping difficulties in which they have problem falling sleep, and keep waking up several time at night which can put parents under extreme exhaustion taking care of them (Goodlin-Jones et al., 2008).

\section{Differences in Parents Gender and Parental Stress}

Gender difference in parenting stress has been investigated in many studies over the world especially in western countries. In a study conducted in Iran , to compare the parental stress among mothers and fathers with autism spectrum using Parental Stress Index Instrument, has 
indicate mothers scored considerably higher than fathers on the three PSI subscales, including the PSI-child domain score, PSI-parent domain score, and overall parental stress index. Therefore as a whole parenting stress indexes in fathers were lower than those in mothers. This finding may not be surprising as in most culture, mothers are more involved than fathers in raising and bringing up their children.

Various study has revealed that mother and fathers go through different dimension of the children s behaviour and deeds as the ones which cause stress. (Krauss 1993; Keller \& Honig 2004). It is also frequently stated that mothers' stress are connected both to child problem behaviours and fathers' mental health, whereas fathers stress level or rating are often not associated with any stressors (Hastings et al., 2005).

In a study that been conducted in Malaysia by Kamarulzaman (2015), to investigate the stress among the Parents of Children with Learning Disabilities and their demographic, shows that the level of stress among mother are higher than fathers of children withlearning disabilities as it is stated that $71.4 \%$ mothers are in the score of high level of stress and about $28.6 \%$ fathers scores high level of stress too. Furthermore, as for low level of stress, the result shows that only $35.1 \%$ are mothers compared to fathers (64.9\%).

This is also supported by many past studies, for instance Hastings et al (2005); Oelofsen and Richardson (2006); Gray (2003) also reported that mothers with learning disabilities experience a greater impact in stress level compared to fathers. As this indicated in a study conducted by Gray (2003) among families of children with autism, results states that mothers and fathers were affected on different ways and levels depending on their child's condition. To add on that, fathers also claimed that child s condition does not impact as the mothers however the stress among father are often from the impact witnessing their wife experiencing the stress with their child (Kamaruddin \& Mamat, 2015).

\section{Differences in Gender among Children with Learning Disabilities and Parental Stress}

There are various study that discussed about the differences in gender among children with learning disabilities also and their intellectual abilities. Conventionally, it is believed that gender do have significant differences in their intellectual capabilities. More male children are reported than female children with learning disabilities. Moreover, it is also been proved as male children often exhibits and expressing and their behavior compared to female children which lead to the perception that the number of male children with learning disorder are much higher compared to female children.

Conversely, it is stated that there are no gender differences in the prevalence of learning disabilities in many current studies. This has been explained Shaywitz et. al (1992) where female children with learning disabilities are often underestimated, as it will lead to risking them in social, emotional and academic challenges by. Though many research has been done to discover and explore the differences in gender in terms of their intellectual abilities, many current studies has concluded that there is no significant differences between male and female children, through many intellectual abilities assessments (Feinstein \& Phillips, 2006).

\section{Methodology}

Material and Methods

Probability sampling method was implemented in this study and total of 120 respondents among parents of children with learning disabilities from Kuala Lumpur has participated in this study. Due to Movement Control Order, study was conducted through online where the 
questionnaires were distributed through google form in various online method such email, and social media. Participants was informed briefly about the objectives of the study, the limits to confidentiality and the related procedure.

In this study, Parenting Stress Index (PSI), 3rd Edition Short Form was used to determine the stress level of the parents Total stress accounts for the stress reported for all the 3 areas with a total of 36 items, including parental distress, stress originated from the relationships and interactions between parent and child and the child (Solis \& Abidin, 1995). Basic information such as participant's gender and their children s gender of are also obtained through the instrument. A summary of social demographic variables was done using descriptive analysis of frequencies. Each subscale has 12 items that are evaluated from 1 (strongly disagree) to 5 (strongly agree), with subscale scores ranging from 12 to 60 . A Total score is calculated by summing the three subscales scores, ranging from 36 to 180 .

\section{Validation \& Reliability}

The Parenting Stress Index Short Form was developed for use with parents of children aged one month to twelve years. Several validation studies are available for this instrument. A study was conducted to measure the validity and internal consistency of Parenting Stress Index Short Form in a Chilean sample including 336 dyads (mean age of mothers 21.4 years; $\mathrm{SD}=7.38$; and mean age of children 84.8 days; $S D=78.0$ ), to exhibiting a high risk of poor health consequences and seeking public primary health care.

As for studies that conducted in Malaysia, it is also reported A study titled The reliability of of parenting stress index-short form (PSI-SF) among caregivers of individuals with learning disabilities by (Nazurah et al., 2016) in Malaysia, it is reported that this instrument has high internal consistency with value $0.90,0.82$, and 0.87 , and the reliability was good with Cronbach's $\alpha=0.944$.

Similarly, in a study titled "Dimensions of stress in parents of children with autistic spectrum Disorder" by (Bakri et al., 2019), also reported to possesses good reliability with an internal consistency of 0.96 or greater for both the $C D$ and PD domains. The alpha reliability coefficients ranged from 0.78 to 0.88 for the $C D$ subscales and 0.75 to 0.87 for the PD subscales. In addition, the test-retest coefficients for this instrument ranged from 0.55 to 0.82 for the CD subscales and 0.69 to 0.91 for the PD subscales. Therefore pilot study was not conducted for this instrument to as it is reported to have high validity and reliability.

\section{Result}

\section{Demographic Findings}

There were 54 fathers or $45 \%$ participated in this study, whereas mothers reported to be slightly more where a total number of 66 or $55 \%$ has participated in this study. As for the children of parents who participated it is reported there were 32 or $26.7 \%$ male children parents has participated in this study. As for female children, there were a total number of 88 or $73.3 \%$ of female children s parents has participated in this study.

\section{Research Objective 1: To Determine the Level of Parental Stress among Parents of Children with Learning Disabilities}

Based on the finding it is stated that the Total Score of Parental Stress reported $97.5 \%$ or 117 parents out of 120 participants with children with learning difficulties in Kuala Lumpur falls under typical stress category, and $2.5 \%$ or only 3 parents reported to have High Stress 
Category. There are none for Clinically Significant Stress reported in this study. It is shown in the Table 1 below:

Table 1 Level of Total Parental Stress

Frequency (f)

Percentage \%

Subscales

\begin{tabular}{lll}
$\begin{array}{l}\text { Typical } \\
\text { Percentiles }\end{array}$ & $\begin{array}{c}\text { StressHigh } \\
\text { Percentiles }\end{array}$ & $\begin{array}{c}\text { StressClinically } \\
\text { Significant Stress } \\
\text { Percentiles }\end{array}$ \\
\hline 115 & 4 & 1 \\
95.8 & 953.3 & 0.8
\end{tabular}

1. Parental Distress (PD)

2. Parent-Child Dysfunctional 114

Interaction (P-CDI) 95.0

3. Difficult Child (DC) 115

$4 \quad 2$

$95.8-4.2$

Total Score 117

$97.5 \quad 2.5$

Mean: 122.44, SD: 10.603

The total mean score for Total Parental Score among parent of children with learning disabilities as mean $=122.44$, (SD: 10.603).

Research Objective 1 a: To Determine the Level of Parental Distress among Parents of Children with Learning Disabilities

As for the first subscale or Parental Distress, it is reported that out of 120 parents, 115 or 95.8\% parents reported to have Typical Stress Percentiles, followed with 4 or $3.3 \%$ reported parents to have High Stress and 1 or $0.8 \%$ parent reported to have clinically significant Stress level.

Research Objective 1 b: To Determine the Level of Parent-Child Dysfunctional Interaction among Parents of Children with Learning Disabilities

For the second subscale it is stated that 114 or $95.0 \%$ reported to have Typical Stress Percentiles, followed by 4 or $3.3 \%$ parents with High Stress and 2 or $1.7 \%$ with clinically significant Stress level.

Research Objective 1 c: To Determine the Level of Difficult Child among Parents of Children with Learning Disabilities

For the last subscale or difficult children it is reported about 115 or $95.8 \%$ parents reported to have Typical Stress Percentiles. As for High Stress, it is reported about that 5 or $4.2 \%$ parents fall under this category and lastly for difficult child, none are reported.

\section{Research Objective 2}

Hypothesis Alternative 1

There is significant differences between parent's gender and parental stress among parents of children with learning disabilities 
An independent sample T Test was conducted to compare the Parental Stress among the parents gender of children with learning difficulties. The Levene Test for homogeneity of variance showed $p<0.05$ thus both groups have the differences value of variance. The result are shown in Table 2.

Table 2: Mean score comparison T- test between gender differences in parental stress among parents of children with learning disabilities.

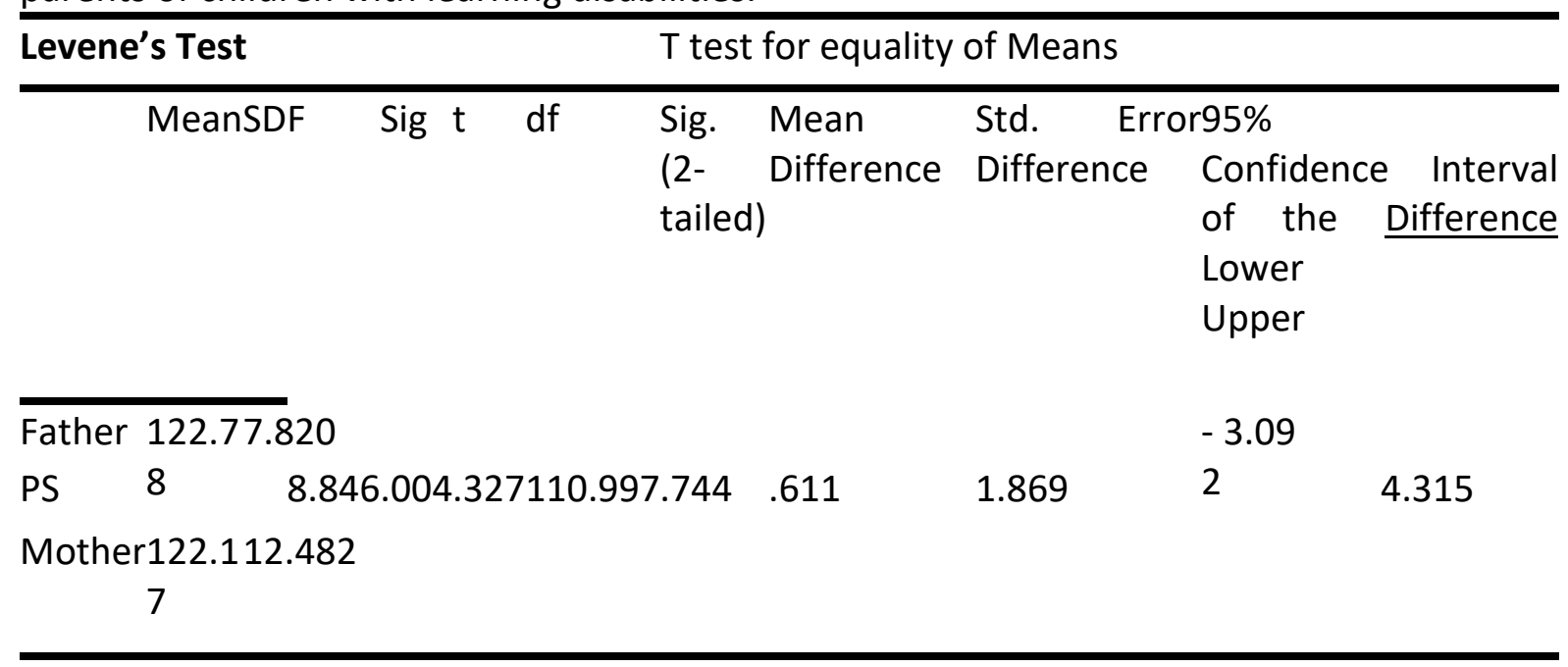

The result of T-test analysis was taken from the equal variance not assumed. Independent $T$ test analysisfor parents gender in parental stress showed that there is no significant difference in the meanscore between father group ( $M: 122.78, S D: 7.82)$ and Mother group $(M: 122.17, S D=12.48)$ with $t(110.997)=.327, p>0.05$. The result reveals that both gender have an equal total scoreof total parental stress level. Therefore, Null hypothesis is failed to be reject due to significantvalue is greater than alpha value.

\section{Research Objective 3}

\section{Hypothesis Alternative 2}

There is a significant differences between children $s$ gender and parental stress among children with learning disabilities in Kuala Lumpur

An independent sample T Test was conducted to compare the Parental Stress among the gender of children with learning difficulties. The Levene Test for homogeneity of variance showed $p>0.05$ thus both groups have the same value of variance.

The result of T-test analysis was taken from the equal variance assumed. Independent $T$ test analysis for children gender in parental stress showed that there is no significant difference in the mean score between father group (M: 123.72, SD: 8.873) and Mother group $(\mathrm{M}: 121.98, \mathrm{SD}=11.18)$ with $\mathrm{t}(118)=0.794, \mathrm{p}>0.05$. 
Table 3 Mean score comparison T- test between gender among children with learning disabilities and parental stress.

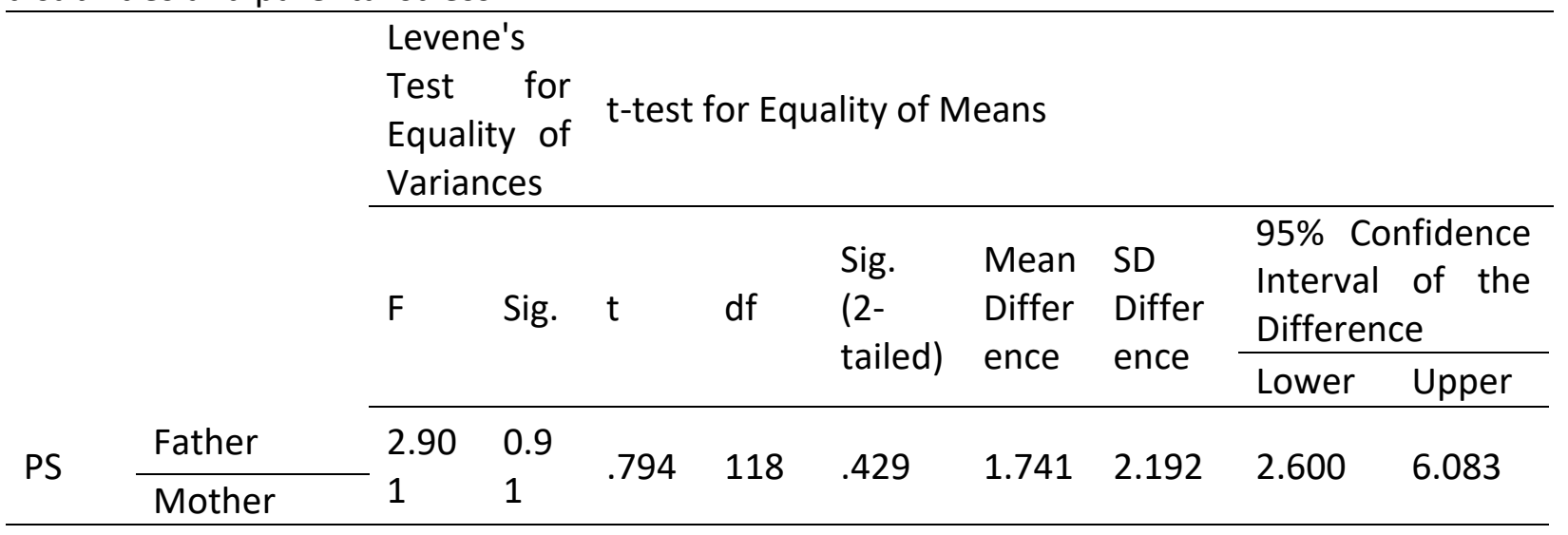

The result reveals that both children's gender have an equal total score of total parental stress level. Therefore, Null hypothesis is failed to be reject due to significant value is greater than alpha value.

\section{Discussion}

Based on this study, the descriptive analysis reported that 117 or $97.5 \%$ parents who have participated in this study, falls under the category of typical stress. The percentile scores that fall between 15 and 80 are considered typical indicates that the stress level is considered normal or moderate. It is also reported about 3 or $2.5 \%$ parent falls under High Stress category which the percentile ranges from $81-89$. None is reported to have clinically significant stress as the range is from 90 and above. Based on the result it can be concluded that all the parents of children with learning difficulties who participated in this study has parental stress however most of them falls under the typical stress level. As a whole, the findings showed that the number of parents who has Learning Difficulties children suffering high stress level are very few $(2.5 \%)$ or 3 parents out 120 participants who participated in this study.

As for the first subscale or Parental Distress, based on the result it is reported that out of 120 parents, 115 or $95.8 \%$ parents reported to have Typical Stress Percentiles, followed with 4 or $3.3 \%$ reported parents to have High Stress and 1 or $0.8 \%$ parent reported to have clinically significant Stress level. This subscale measures the parents perception of their own behavior including perceived competence, such as Item 12 "Don't enjoy things as I used to" as it reports to have the highest mean score 4.00 where most of the parent agrees with the Med: 4 (Agree) and Item 1 "Feel that I cannot handle things" with the Med: 3.09 and Med: (Agree). Additionally PD is reported to be the highest score as it is referring to mothers or fathers reflection of their personal adjustment to parenthood. The questions in this subscale comprise a variety of measures designed to assess the discomfort experienced by a parent as a result of specific personal traits connected to the parenting role such as depression, pessimism, burnout, feeling trapped, and so on (Solis \& Abidin, 1995).

For the second subscale, the items measures the extent of parents satisfaction with their child and their interactions with them as it is reported that 115 or $95.8 \%$ parents reported to have Typical Stress Percentiles, followed with 4 or $3.3 \%$ reported parents to have High Stress and 1 or $0.8 \%$ parent reported to have clinically significant Stress level in Parent 
Child Dysfunctional Interaction. Referral to professional intervention also will be suggested to this parent. This is because a high score in this measure suggests that the parents are disappointed, rejected, or alienated from their kid, as well as a lack of bonding with the child. However, a substantial percentage of parents experience usual stress.

Difficult child refers to the children who may be experiencing difficulties with selfregulation processes in both physical and temperamental issues which also refers to item number 31 "Child's sleeping or eating schedule hard to establish" has the second highest Mean score: 3.83 with the Med of 4 which indicates that most parents agree to this item. This also has been proved in a study, that sleeping difficulties or disturbance are prevalent in children with learning difficulties and it is often connected with parenting stress. (Bartlett, Rooney and Spedding, 1991). These parents could benefit from help with strategies to handle challenging behavior, and more information about age-appropriate discipline.

To add on more, the typical stress level among parents has shown the higher rate compare to least number on high stress and barely on clinically stress score, this is could be explained by a research done by (Ilias et al., 2008), that the effectiveness of psycho education program on parents' psychosocial well beings that shows tremendous difference as the a group of parents with special children shows that there were differences in term of parental stress as well as psychological wellbeing before and after they attended the program. Parent education, training or psychoeducation has been defined as "treatment procedures in which parents are trained to alter their child's behaviour at home" (Kazdin, 1997). Therefore educating parents and proper training is has become widely regarded as essential component of helping children with disabilities which eventually helps to manage parents stress level (Sofronoff \& Farbotle, 2002).

As a whole, result of this study shows that there is no significant difference in gender among parents of parents with learning difficulties both. According to the result, it is indicated mother are only slightly higher than father in total parental stress score with the mean score. In a similar study that was conducted by Dr. Shahzadi Malhotra, also indicate that there are no gender differences in parenting stress among parents of children with autism.

Although there are no statistically significant differences in parental stress between men and women, there are variances in how mothers and fathers experience stress based on their own and their children's traits. This is likely due to the fact that both moms and fathers encounter problems and stresses in their own way. For instance moms may be overloaded by their child's adaptive requirements, while dads may be stressed by the added financial strain of meeting the higher financial needs to cover the medical and rehabilitation costs of a kid with learning difficulties. (Malhotra et al., 2015).

Based on this study's finding, it is stated that there is no differences in children $\mathrm{s}$ gender and Parental Stress among parents of children with learning difficulties. This is supported by some of study that has been conducted previously. According to the study, Comorbid learning disorders occurred as frequently in learning disorders such as Reading spelling and arithmetic problems and the findings suggest for the gender ratios, more boys than girls showed spelling deficits, while more girls were impaired in arithmetic therefore both gender equally reported same level of issues. Therefor both gender could lead to parental stress equally (Moll et al., 2014). 
The implication of this study is to provide better understanding about parental stress among parents of children with learning disabilities. Policies and facilities have to implement in order to help and to minimize the burden of those family with disabled children. Moreover, suitable and appropriate parenting courses and training should be provided to parents with children with special needs. As a whole, it is undoubtedly that the parent will go through stress, limited financial support, lack of time and emotional and physical exhaustion, however stress need to be handle in a proper way. Therefore based on the result of the present study, it is important to provide a continuous education and counseling programs as it necessary to improve parents coping patterns toward care of their disabled children through discussing child problems and needs and parents mental health.

As for the recommendation, future researcher can enlarge the samples to more states in Malaysia as this study only covers parents from Kuala Lumpur. Moreover more demographic variables can be added in future studies such as age group of parents, social economic status in order to explore more variables data. As for future research, studies on policies and approaches on contributing to minimize parent's challenges which indirectly will minimize the stress level should be conducted.

\section{Conclusion}

As a conclusion, this study examined the level of the level of parental stress among parents of children with learning disabilities in Kuala Lumpur, which comprises three subscales, Parent Distress, Parent Child Dysfunction Interaction, and Difficult Child which show most of parent's falls under the typical stress category. Besides that, the gender differences among parents and children s gender and parental stress are also examined which resulted as there is no differences in both gender with parental stress.

This study provides a better understanding about parental stress among parents of children with learning disabilities. Relevant policies and facilities have to be implemented in order to help and to minimize the burden of those family with disabled children. Besides that suitable and appropriate parenting courses and training should be provided to parents with children with special needs. As a whole, it is undoubtedly that the parent will go through stress, limited financial support, lack of time and emotional and physical exhaustion, however stress need to be handle in a proper way. Therefore based on the result of the present study, it is important to provide a continuous education and counseling programs as it necessary to improve parents coping patterns toward care of their disabled children through discussing child problems and needs and parents mental health.

\section{References}

Ahmad, N., MuhdYusoff, F., Ratnasingam, S., Mohamed, F., Nasir, N. H., MohdSallehuddin, S., ... \& Aris, T. (2015). Trends and factors associated with mental health problems among children and adolescents in Malaysia. International Journal of Culture and Mental Health, 8(2), 125-136.

Amar, H. S. S. (2008). Meeting the needs of children with disability in Malaysia. Med J Malaysia, 63(1), 1

Aracena, M., Gómez, E., Undurraga, C., Leiva, L., Marinkovic, K., \& Molina, Y. (2016). Validity and reliability of the Parenting Stress Index Short Form (PSI-SF) applied to a Chilean sample. Journal of Child and Family Studies, 25(12), 3554-3564.

Armstrong, M. I., Birnie-Lefcovitch, S., \& Ungar, M. T. (2005). Pathways between social 
support, family wellbeing, quality of parenting, and child resilience: What we know. Journal of Child and Family Studies, 14(2), 269-281.

Badger, T. A. (1996). Family members' experiences living with members with depression. Western Journal of Nursing Research, 18(2), 149-171.

Bahry, N. S., Mat, A., Kori, N. L., Ali, A. M., Abdul Munir, Z., \& Salleh, M. Z. M. (2019). Challenges faced by Malaysian parents in caregiving of a child with disabilities. Bahry, NS, 118-124.

Baqutayan, S. M. S. (2015). Stress and coping mechanisms: A historical overview. Mediterranean Journal of Social Sciences, 6(2 S1), 479-479.

Bernstein, G. A., \& Borchardt, C. M. (1991). Anxiety disorders of childhood and adolescence: A critical review. Journal of the American Academy of Child \& Adolescent Psychiatry, 30(4), 519-532.

Bohon, C. (2019). Binge eating disorder in children and adolescents. Child Adolescent Psychiatry Clin N Am, 28, 549-555.

Booth, T., \& Booth, W. (1996). Parental competence and parents with learning difficulties. Child \& Family Social Work, 1(2), 81-86.

Chadda, R. K. (2014). Caring for the family caregivers of persons with mental illness. Indian Journal of Psychiatry, 56(3), 221.

Cohen, J. (1992). Statistical power analysis. Current Directions in Psychological Science, 1(3), 98-101

Corrigan, P. W., \& Miller, F. E. (2004). Shame, blame, and contamination: A review of the impact of mental illness stigma on family members. Journal of Mental Health, 13(6), 537-548

Dyson, L. L. (1996). The experiences of families of children with learning disabilities: Parental stress, family functioning, and sibling self-concept. Journal of Learning Disabilities, 29(3), 280-286

Edition, F. (2013). Diagnostic and statistical manual of mental disorders. Am Psychiatric Assoc, 21

Everly, G. S., \& Lating, J. M. (2002). The anatomy and physiology of the human stress response. A clinical guide to the treatment of the human stress response, 15-48.

Freedman, R. I., Litchfield, L. C., \& Warfield, M. E. (1995). Balancing work and family: Perspectives of parents of children with developmental disabilities. Families in Society, 76(8), 507-514

Hobfoll, S. E. (1989). Conservation of resources: a new attempt at conceptualizing stress. American Psychologist, 44(3), 513.

Holmes, A. M., \& Deb, P. (2003). The effect of chronic illness on the psychological health of family members. Journal of Mental Health Policy and Economics, 6(1), 13-22

Hoagwood, K. E., Cavaleri, M. A., Olin, S. S., Burns, B. J., Slaton, E., Gruttadaro, D., \& Hughes, R. (2010). Family support in children's mental health: A review and synthesis. Clinical child and family psychology review, 13(1), 1-45.

Ilias, K., Ponnusamy, S., \& Normah, C. D. (2008). Parental stress in parents of special children: The effectiveness of psychoeducation program on parents' psychosocial well beings. Simposium Sains Kesihatan Kebangsaan Kuala, 18-19.

Isa, S. N. I., Ishak, I., Ab Rahman, A., Saat, N. Z. M., Din, N. C., Lubis, S. H., \& Ismail, M. F. M. (2016). Perceived Stress among Malay Caregivers of Children with Learning Disabilities in Kelantan. Malaysian Journal of Health Sciences/Jurnal Sains Kesihatan Malaysia, 14(2), 
Kamaruddin, K., \& Mamat, N. (2015). Stress among the parents of children with Learning Disabilities: A Demographical Analysis. International Journal of Humanities Social Sciences and Education, 2(9), 194-200.

Kvist, A. P., Nielsen, H. S., \& Simonsen, M. (2011). The effects of children's ADHD on parents' relationship dissolution and labor supply.

Gubman, G. D., \& Tessler, R. C. (1987). The impact of mental illness on families: Concepts and priorities. Journal of Family Issues, 8(2), 226-245.

Malhotra, S., Khan, W., \& Bhatia, M. S. (2015). Gender Differences in Stress among Parents of Children with Autism.

Mahoney, F. P. (2009). The relationship between parenting stress and maternal responsiveness among mothers of children with developmental problems (Doctoral dissertation, Case Western Reserve University).

Margalit, M., Al-Yagon, M., \& Kleitman, T. (2006). Family subtyping and early intervention. Journal of Policy and Practice in Intellectual Disabilities, 3(1), 33-41.

Marsh, D. T., \& Johnson, D. L. (1997). The family experience of mental illness: implications for intervention. Professional Psychology: research and practice, 28(3), 229.

Mazzone, S., \& Nader-Grosbois, N. (2017). Emotion-Related Socialization Behaviours in Parents of Children with an Autism Spectrum Disorder. Psychology, 8(08), 1134.

Masi, G., Mucci, M., \& Millepiedi, S. (2001). Separation anxiety disorder in children and adolescents. CNS drugs, 15(2), 93-104.

McBride, B. A., Schoppe, S. J., \& Rane, T. R. (2002). Child characteristics, parenting stress, and parental involvement: Fathers versus mothers. Journal of Marriage and Family, 64(4), 998-1011.

Miller, G. E., \& Chen, E. (2010). Harsh family climate in early life presages the emergence of a proinflammatory phenotype in adolescence. Psychological Science, 21(6), 848-856.

Moll, K., Kunze, S., Neuhoff, N., Bruder, J., \& Schulte-Körne, G. (2014). Specific learning disorder: Prevalence and gender differences. PLoS one, 9(7), e103537.

Musa, R. B., \& Shafiee, Z. A. S. M. A. N. I. (2007). Depressive, anxiety and stress levels among mothers of ADHD children and their relationships to ADHD symptoms. AJP, 8, 20-28.

Nadeem, M., Choudhary, F. R., Parveen, A., \& Javaid, F. (2016). Parental Stress among Parents of Children with and without Disabilities. Pakistan Journal of Social Sciences (PJSS), 36(2).

Phetrasuwan, S., \& Miles, S. M. (2009). Parenting stress in mothers of children with autism spectrum disorders. Journal for Specialists in Pediatric Nursing, 14(3), 157-165.

Ousley, O., \& Cermak, T. (2014). Autism spectrum disorder: defining dimensions and subgroups.

Petretto, D. R., \& Masala, C. (2017). Dyslexia and specific Learning Disorders: New International Diagnostic Criteria.Urrent Developmental Disorders Reports, 1(1), 20-28.

Ozturk, Y., Riccadonna, S., \& Venuti, P. (2014). Parenting dimensions in mothers and fathers of children with Autism Spectrum Disorders. Research in Autism Spectrum Disorders, 8(10), 1295-1306

Ranta, R. S., Sharma, V. K., \& Gupta, P. (2015). Parenting stress and need assessment of families with disabled children across Himachal Himalaya. Assessment, 3(2).

Resch, J. A., Benz, M. R., \& Elliott, T. R. (2012). Evaluating a dynamic process model of wellbeing for parents of children with disabilities: A multi-method analysis. Rehabilitation Psychology, 57(1), 61.

Sanders, J. L., \& Morgan, S. B. (1997). Family stress and adjustment as perceived by parents 
of children with autism or Down syndrome: Implications for intervention. Child \& Family Behavior Therapy, 19(4), 15-32.

Speaks, A. (2011). What is autism? Retrieved on November, 17, 2011

Schulz, R., \& Sherwood, P. R. (2008). Physical and mental health effects of family caregiving. Journal of Social Work Education, 44(sup3), 105-113.

SI, O., VY, L., \& AR, F. N. (2017). Parenting stress among Malaysian parents of children with Autism Spectrum Disorder (ASD). Med \& Health Jun 2017; 12(1): 42-55.

Soltanifar, A., Akbarzadeh, F., Moharreri, F., Soltanifar, A., Ebrahimi, A., Mokhber, N., \& Naqvi, S. S. A. (2015). Comparison of parental stress among mothers and fathers of children with autistic spectrum disorder in Iran. Iranian Journal of Nursing and Midwifery Research, 20(1), 93.

Solis, M. L., \& Abidin, R. R. (1991). The Spanish version parenting stress index: A psychometric study. Journal of Clinical Child and Adolescent Psychology, 20(4), 372-378.

Tan, K. L., \& Yadav, H. (2008). Assessing the development of children with disability in Malaysia. The Medical Journal of Malaysia, 63(3), 199-202.

Theule, J., Wiener, J., Tannock, R., \& Jenkins, J. M. (2013). Parenting stress in families of children with ADHD: A meta-analysis. Journal of Emotional and Behavioral Disorders, 21(1), 3-17.

Valicenti-McDermott, M., Lawson, K., Hottinger, K., Seijo, R., Schechtman, M., Shulman, L., \& Shinnar, S. (2015). Parental stress in families of children with autism and other developmental disabilities. Journal of Child Neurology, 30(13), 1728-1735.

Walton-Moss, B., Gerson, L., \& Rose, L. (2005). Effects of mental illness on family quality of life. Issues in mental health nursing, 26(6), 627-642.

Weiss, G., \& Hechtman, L. T. (1993). Hyperactive children grown up: ADHD in children, adolescents, and adults. Guilford Press.

Zaidman-Zait, A., Mirenda, P., Zumbo, B. D., Wellington, S., Dua, V., \& Kalynchuk, K. (2010). An item response theory analysis of the Parenting Stress Index-Short Form with parents of children with autism spectrum disorders. Journal of Child Psychology and Psychiatry, 51(11), 1269-1277 